\title{
TEXTILE-CIRCUIT - the opportunity of integrating functionality into a textile product
}

\author{
Sophia Krinner ${ }^{1}$, Michael Kieren ${ }^{1}$ \\ ${ }^{1} K A R L$ MAYER R\&D GmbH, Obertshausen, Germany
}

\section{INFO}

CDAPT, ISSN 2701-939X

Communication

2020, Vol. 1, No. 1, pp. 74-79

DOI:10.25367/cdatp.2020.1.p74-79

Received: 30 May 2020

Accepted: 08 August 2020

Available online: 20 November 2020

\begin{abstract}
With its technology KARL MAYER provides the possibility to use tailored fiber placement of functional yarns directly during the textile production process. It allows a fast production of functional fabrics with no additional steps while keeping the desired textile properties.

These functional warp knitted products can be used in a wide range of applications such as active- and sportswear, lingerie, outdoor, automotive and agricultural fabrics.
\end{abstract}

\section{Keywords}

Warp knitting,

Electronic Textiles,

Textile sensors,

Wearables,

Tailored fiber placement

(C) 2020 The authors. Published by CDAPT.

This is an open access article under the CC BY-NC-ND license https://creativecommons.org/licenses/ peer-review under responsibility of the scientific committee of the CDAPT.

\section{Introduction}

The idea of electronic textiles has been around for many years now and very interesting products have been launched to the market already. First products for the monitoring of vital parameters have already been developed in the nineties [1]. Those products got a lot of attention but still they could not achieve a breakthrough in the market.

We at KARL MAYER have been thinking about the reasons for this and found several obstacles that still exist for these products. Many researchers direct their activities to important topics like washability [2] and standardization of electronic textiles [3], which will improve the future products a lot. In our opinion there are still some topics missing that will be essential for a good wearer experience.

One very important topic is the price. Current smart garments tend to be expensive and are therefore not used for the daily life. The widely known jacket, which was developed by Jacquard ${ }^{\mathrm{TM}}$ by Google and Levi's ${ }^{\circledR}$ currently sells for 248 \$4], while permitting to operate your phone when interacting with your jacket, but not adding new function to the wearers' environment. This might be fine for a jacket that will 
not be needed every day, but underwear or regular clothing that you will need in a higher amount has to be affordable for everyone. While the price in case of the jacket might depend a lot on the big names of the developing companies, there are also other factors that make the products expensive.

The electrically conductive materials are more expensive than regular yarn materials. This is the one parameter we cannot change as a machinery manufacturer. What we can do is improving the textile production process. Currently a textile is produced and functionality is added later in a second step. Often these steps don't happen at the same place and are done by people with technological knowledge for this one step only. But as everyone knows, time, transport and human resources make the production more expensive and therefor also the product itself. For this reason, our approach is to reach an almost ready-made product in only one step.

Another important issue is the textile itself. All processes of functionalization have one thing in common. They add something that will change the behavior of the textile. Glued sensors will always be noticeable even if they are flexible, they will act differently than a textile. They will stick to your skin when you sweat and prevent the transport of moisture. Also the risk of delamination shortens the lifecycle of the product. Even embroidered areas will change the flexibility of a textile. Our solution is to already produce the functional textile with the properties needed and not intervene with their characteristics later on.

\section{KARL MAYER's String bar technology and its original use}

For this approach KARL MAYER uses their string bar technology. It is applied in a raschel machine that can do open, closed, elastic and rigid ground structures. It can also be combined with the Jacquard technology that permits designing the ground structure in terms of optical and also functional matters, meaning that you will be able to construct zones of different elasticity or air permeability.

In this ground structure you will be able to place your functional yarns. With our string bar system, you do not use ground bars full of guide needles but single guide fingers that place yarns on defined spots in the fabric. You are able to design lines but also form closed areas out of one or more functional yarns.

(a)

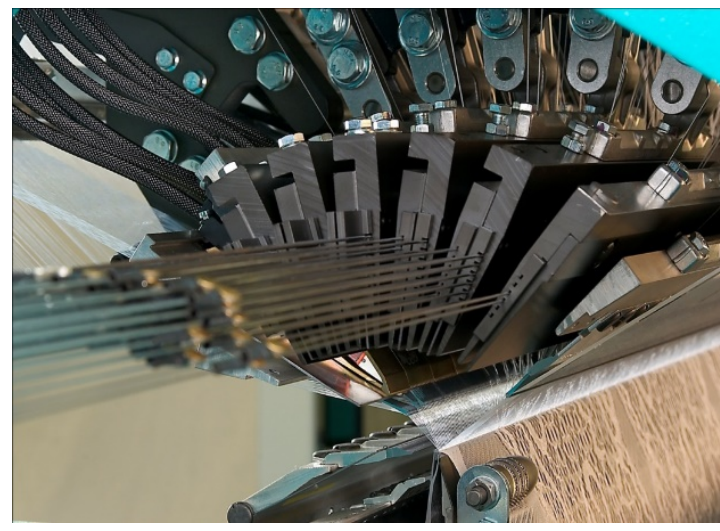

(c)

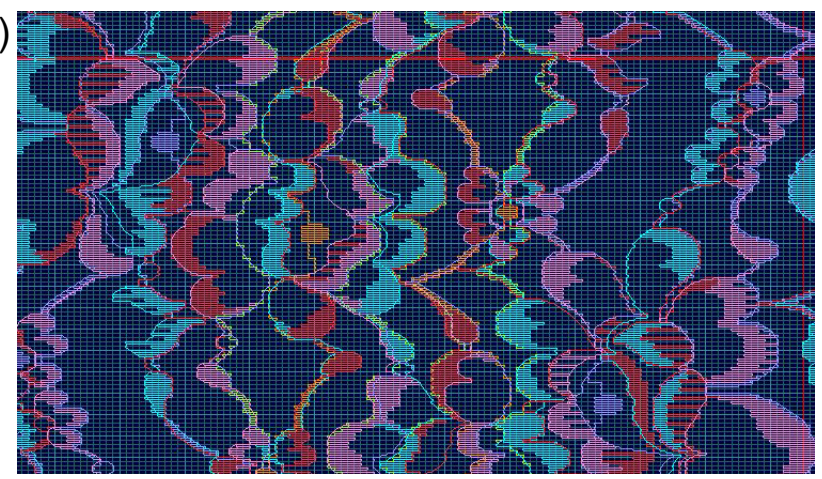

(b)

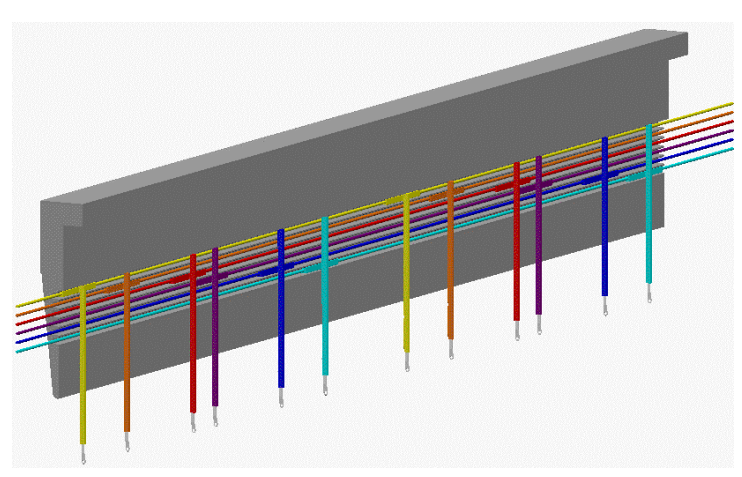

(d)

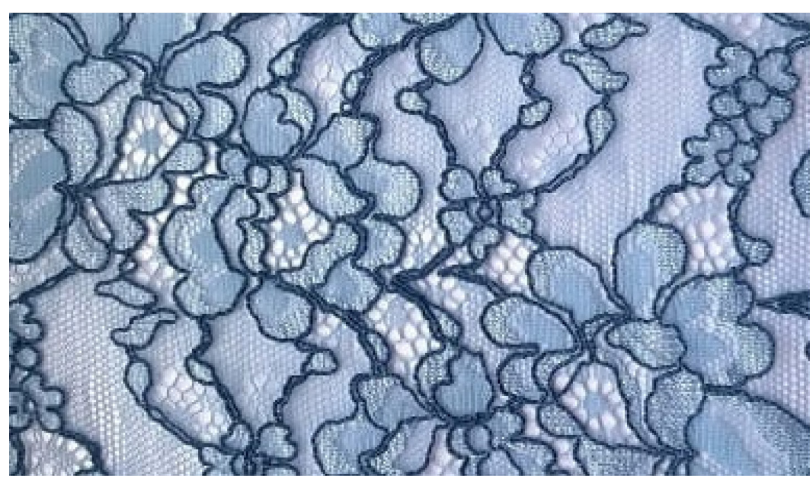

Fig. 1 (a) Knitting area of a string bar machine; (b) schematic depiction of string bars; (c) CAD-drawing of yarnplacement; (d) original fabric produced from the drafting 
The yarns are guided into the textile from a creel. You can place your bobbin there and use a variety of different materials at the same time.

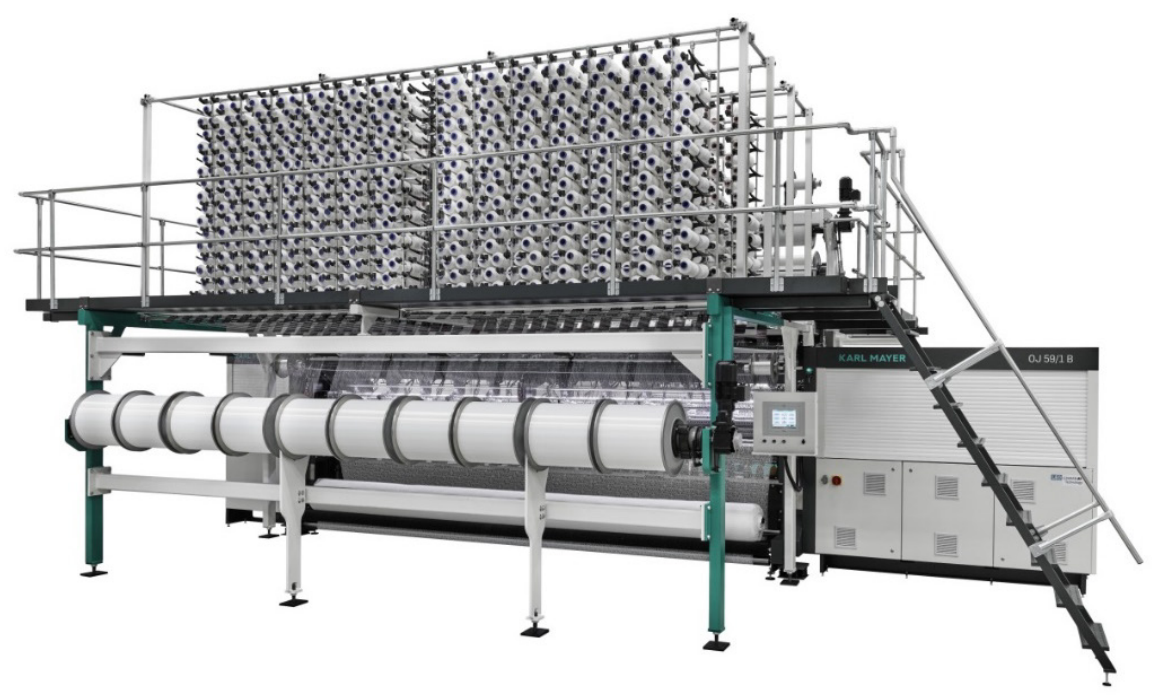

Fig. 2 (a) Example of a stringbar machine

This technology has originally been developed for the production of lace fabric and owes its great flexibility to the different designs and materials that are a crucial part of these types of fabric. It has, however, been applied to the technical field before.

Our composite machines are known for their production of strong, lightweight non-crimp fabric that can be used as prepeg structures for automotive and aircraft industries [5]. Those fabrics often consist of glass filaments and carbon fiber. Using carbon fiber in the complete fabric, however, can be very expensive given the fact that supportive carbon structures might not be necessary in the complete fabric.

This has led to the combination of or composite machines and the stringbar system. This link of technologies allows to form a base of adequate ground filaments and apply stronger, more expensive material in the shapes and amounts that are necessary already during the production of the textile, while keeping the cost at a reasonable level [6].

(a)

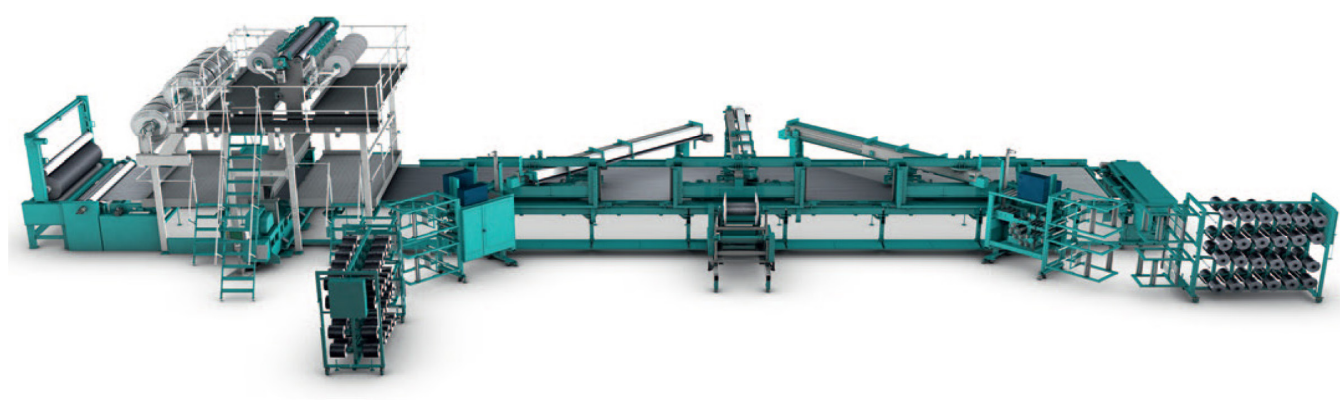

(b)

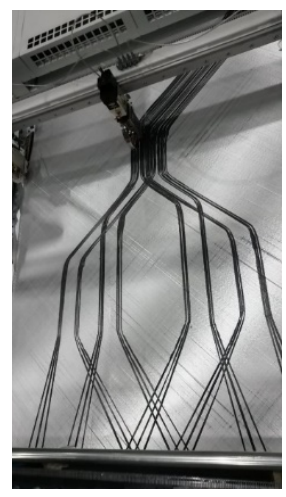

Fig. 3 (a) Example of a composite machine; (b) example of positioned carbon fibers in a non-crimp fabric 


\section{Applying string bar technology to electronic textiles}

These advantages can also be applied to the area of electronic textiles. In our project TEXTILE-CIRCUIT we have been modifying existing KARL MAYER machines to work with different functional materials for the creation of smart textile applications.

Our successful prototypes contain a coil for inductive charging, a textile control panel and variations of a smart shirt.

For our coil we have applied insulated conductors during the warp knitting process. These form the necessary coil structure to generate an electromagnetic field. The coils are designed to match the ones that are integrated in the new generations of smart phones and are therefore able to transmit energy to them. They can also be applied for other charging systems.

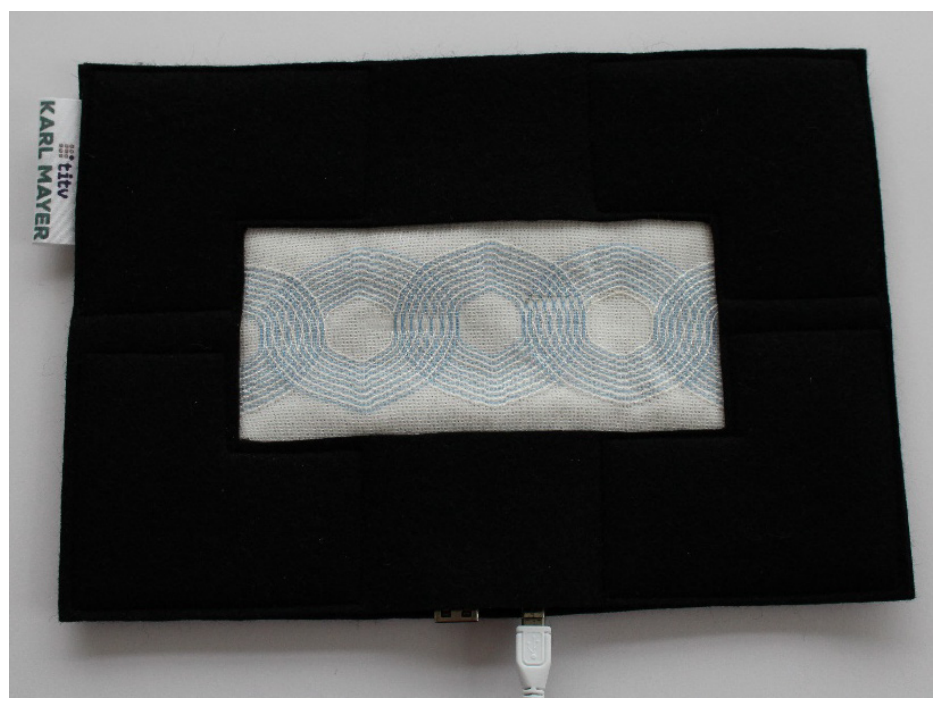

Fig. 4 Fully textile inductive charging pad

For our control panel we have designed buttons that are formed by single conductive yarns. In this case we decided on non-isolated yarns to permit interaction with the skin. Each button consists of two areas that are isolated from each other but have been connected to one circuit. By touching those areas, the skin closes the circuit and a signal can be sent. All buttons are connected to a control platform that permits the transmission of different signals.

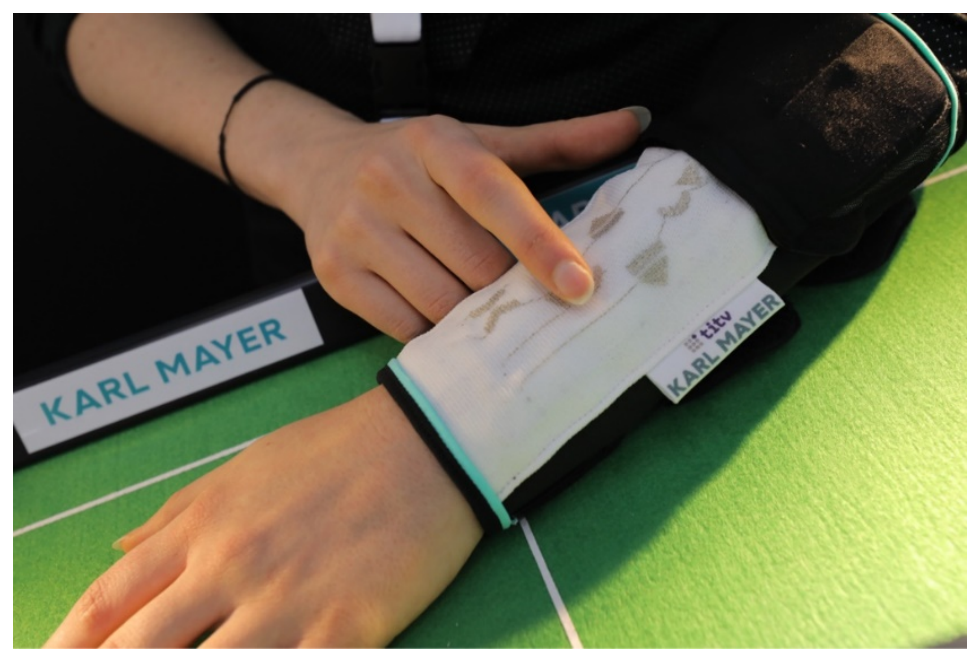

Fig. 5 Textile control panel

During our work on a smart shirt, we came up with different solutions. Our first approach was to include flat textile electrodes by forming conductive areas with non-isolated threads. Those electrodes have to have a good contact to the skin to be able to measure the heartrate of the wearer. We also decided to 
integrate a humidity sensor and a temperature sensor. For our humidity sensor we decided on a resistive system. Two parallel conductors measure the electrical resistance between them and are therefore able to detect an increase of moisture with the increase of conductivity between them. Our temperature sensor is a textile thermocouple. We have integrated copper and constantan wires that detect the temperature at their meeting point inside the fabric. All data is transported into an electric box via knitted conductors. It is collected there and can be sent to any device via Bluetooth.

(a)

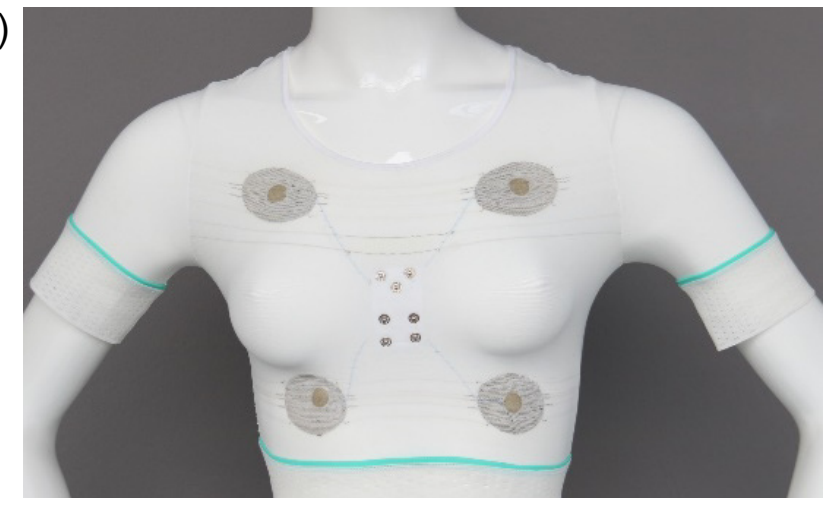

(b)

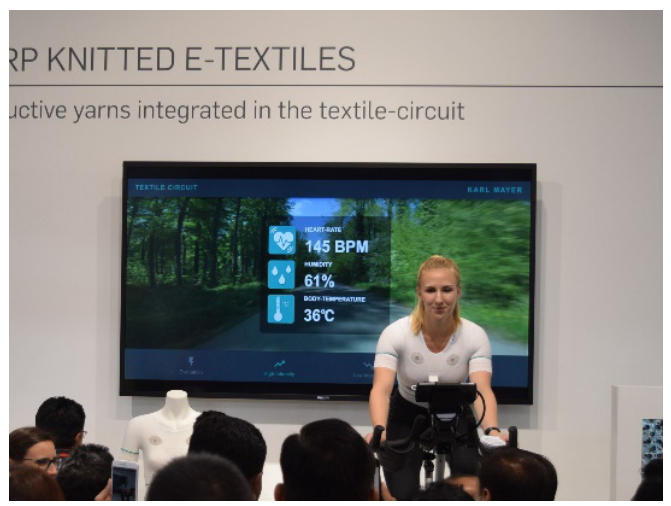

Fig. 6 (a) First smart shirt with detection of heartrate, temperature and humidity; (b) live demonstration with displayed vital signs

In our second approach we saw the need to improve the heartrate sensor. As the flat electrodes had to stay on the exact same spot for a good signal, our first shirt had to be designed very tight. To increase the comfort of the wearer we improved our electrode structure. The electrodes still have to stay at the same place for the measurement and need constant skin contact, but by forming raised electrodes we were able to decrease the pressure on the body during the measurement. Another benefit is that the electrodes are only visible at one side of the fabric, which makes it an ordinary shirt from the outside.

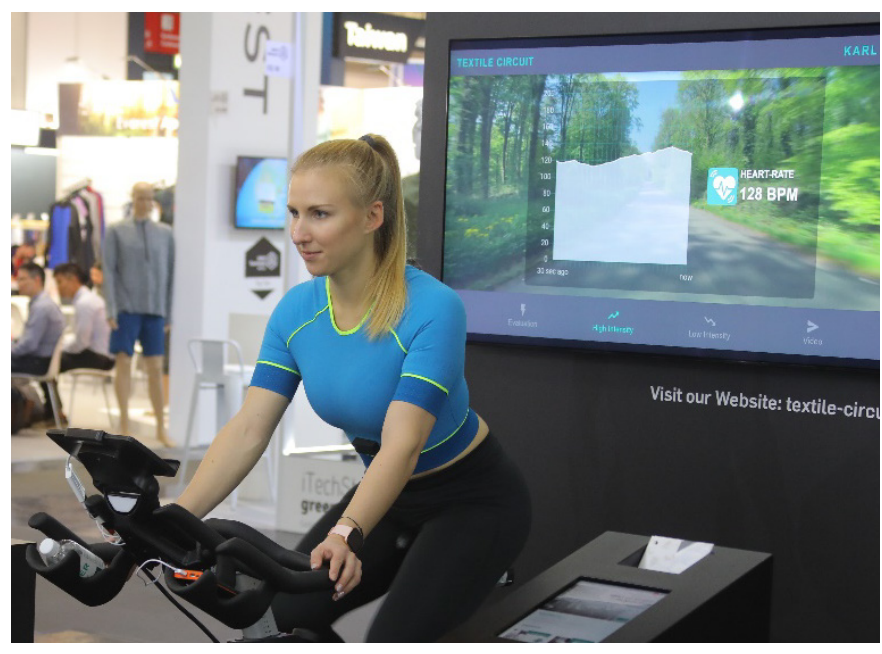

Fig. 7 Improved smart shirt with new sensing system

\section{Materials and challenges}

During our trials for different applications, we had the opportunity to work with many different materials that are already available in the market. Although not every yarn can be currently used with our technology, we were able to find a good spectrum to cover different functionalities.

The products necessary can basically been divided into two groups, non-insulated and insulated materials. For the first group there are in principle two limitations that concern surface and strength of the yarns. Regarding surface it is important to have a highly even product, which eliminates almost all staple fiber products. Those will be mostly destroyed due to friction during the knitting process. In terms of strength, it is very important that the materials can endure bending and traction at the same time. This is especially a difficult task for metal filaments like copper. This essentially leaves us with the group of 
metal coated filament yarns. Those surfaces are still being improved [7]. Yet we were already able to achieve very good results with the current materials and successfully performed basic finishing and washing processes.

The second group are the insulated materials. In this case the material itself is protected by a coating, which mostly eliminates problems with friction. The coating itself often raises other difficulties. Major problems are the increased diameter and decreased flexibility of the material. During the production process all materials have to be guided in small guide fingers and also move in the gap between the knitting needles. The finer a fabric has to be, e.g. for applications in clothing, the smaller those gaps get. Materials with high diameters cannot be used in such cases. They will also be a source of irritation in the fabric later. Low flexibility of the material will even increase the problems during the knitting process. The yarn might be thin enough, but if it cannot be bend in small angles, it will not stay in the right needle gap and might be destroyed during the knitting process or destroy the knitting elements itself.

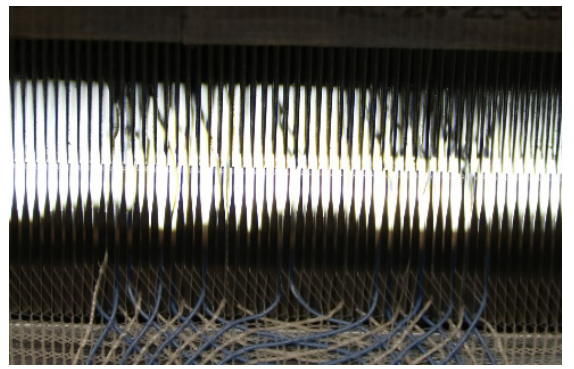

Fig. 8 Insulated yarn in the knitting area bending the needles

The challenge is to find the right combination of machine gauge and yarn count to match the product that has to be achieved and the function it will have.

\section{Conclusions}

Our string bar technology is a great opportunity of fast production of electronic textiles that also increases the experience of the wearer of smart garments. To bring this potential into an applicable technology for industrial productions, there are still some steps of modification on warp knitting machines needed.

Our goal is to support the development of electronic textiles and prepare the technology to enter production as soon as the demand for new products is growing.

\section{References}

[1] Quinn, B. Textile Futures: Fashion, Design and Technology, Berg, Oxford, 2010, p.12.

[2] Rotzler, S. Reliability and Washability of Textile-Based Circuit Boards; IPC E-Textiles Europe; Munich, Germany, 12-11-2019.

[3] Ullrich, K. Smart Textiles, auf die man sich verlassen kann - Vorstellung des Smart-Textiles-Prüflabor des TITV; Symposium Smart Textiles, SmartTex Netzwerk, Weimar; Deutschland, 29.01.2019.

[4] Levi's ${ }^{\circledR}$ Sherpa Trucker Jacket With Jacquard ${ }^{\mathrm{TM}}$ By Google. Available online: https://www.levi.com/US/en_US/apparel/clothing/tops/levis-sherpa-trucker-jacket-with-jacquard-bygoogle/p/773710001 (accessed on 09.07.2020).

[5] Herrmann, A. S., Eberth, U. Technische Textilien für Luftfahrt- und Fahrzeuganwendungen. In: Knecht, P. (Editor), Technische Textilien, Deutscher Fachverlag, 2006.

[6] Markgraf S.; Heinecke, T.; Nendel, S.; Kirchberg, A. KonText - Großserientaugliche Kett- und Schussfadenversatz-Technologie; 16. Chemnitzer Textiltechniktagung; Chemnitz, Germany, 29-05-2018.

[7] Cramer, J.; Neudeck, A.; Möhring, U. Mit Elektrochemie zu waschbeständigen metallisierten Garnen, Galvanotechnik 3/2019, pp. 451-456, Eugen G. Lenze Verlag. 